\title{
Design Thinking as a Mindset Shift for Innovation in Healthcare
}

Patrizia Marti

Università degli Studi di Siena

marti@unisi.it

ORCID 0000-0002-2448-8747

Annamaria Recupero

Università degli Studi di Siena

annamaria.recupero@unisi.it

ORCID 0000-0003-2686-4010

Cecilia Goracci

Università degli Studi di Siena

cecilia.goracci@unisi.it

ORCID 0000-0002-3262-6492
Flavio Lampus

Università degli Studi di Siena

flavio.lampus@unisi.it

ORCID 0000-0002-1207-6139

Lorenzo Franchi

Università degli Studi di Firenze

lorenzo.franchi@unifi.it

ORCID 0000-0002-2072-460X

Simone Guercio

Università degli Studi di Siena

s.guercio@gmail.com

ORCID 0000-0002-7723-7132

\section{Alessandro Vichi}

University of Portsmouth

alessandrovichi1@gmail.com

ORCID 0000-0002-1158-5388

\begin{abstract}
Design Thinking is a human-centred approach to problem solving and innovation that exploits design theories and methods to solve ill-defined problems. Recently it has been a popular subject of real-life applications in research and industrial endeavours for its original way to combine creative and analytical thinking, what is desirable from a human viewpoint with what is technologically feasible. This paper focuses on the application of Design Thinking in paediatric orthodontics. Through the analysis of a design case study, the paper picks up the threads of the challenges of devising a facemask for maxillary malocclusion. The case study shows how a Design Thinking mindset can make a holistic and creative approach flourishing, bringing together different competences at any stage of the design process. The methods of design allowed to translate the different languages of the stakeholders into a single narrative where the people's journeys are clearly depicted, monitored, and supported.
\end{abstract}

\author{
Keywords \\ Design Thinking \\ Human-centred design \\ Healthcare \\ Children \\ Maxillary malocclusion
}




\section{Introduction}

In a seminal article, the design theorist Richard Buchanan coined the label "Design thinking" to describe the thought processes of designing "to connect and integrate useful knowledge from the arts and sciences alike, but in ways that are suited to the problems and purposes of the present" (Buchanan, 1992, p. 6). Buchanan theorised a new role of the designer in exploring knowledge integration combining theory and practice for "new productive purposes".

In the past two decades, Design Thinking has seen a steady increase in use becoming popular in several fields including business for seeking innovation (Brown, 2009), education for teaching creative problem-solving (Baker \& Moukhliss, 2020), and in design as a valuable tool for analysing how designers think while designing, including recent attempts at synthesis with social sciences (Calgren et al., 2016) and reflective perspectives (Cooper, 2019; Verganti, 2008).

The proliferation of a wide academic literature and media articles has demonstrated a lively debate around the approach, in particular outside the realm of design (Carlgren et al., 2016).

Johansson-Sköldberg et al. (2013) depicted the landscape in two distinct macro-discourses: Designerly Thinking and Design Thinking.

The first one is rooted in the academic field of design and refers to the design practice and the theoretical reflections characterising the competence of the designer.

The second one refers to the attempt of exploring the design practice and competences beyond the design context engaging people without a scholarly background in design in the design process. In this respect, Design Thinking can be seen as a simplified version of Designerly Thinking in the attempt to disseminate a human-centric culture to boost innovation.

In the following, we focus on recent applications of Design Thinking in the medical field, an area which requires continuous innovation to meet emerging needs and expectations of a multistakeholder system (Altman et al., 2018). Unfortunately, most of the new systems and processes are designed without really taking the human point of view, resulting in solutions which are unused, unaccepted and inefficient.

Bon Ku and Ellen Lupton (2020) coined the term Health Design Thinking to indicate a mindset and a pool of design methods applied to the challenges of medicine. A central tenet of Health Design Thinking is to look at people not as patients defined by illness or impairment, but more holistically as individuals. This is achieved by applying design methods to empathise and co-design with patients and any other actors playing a role in caring for them.

The research described in this article presents a design case study which developed an innovative solution of facemasks for the treatment of Class III malocclusions in children. This is a growth-related dentofacial deformity characterised by mandibular prognathism in relation to the maxilla and/or cranial base (Zere et al., 2018). The misalignment of the teeth on the higher and lower arches can give rise to disorders that invest not only the mouth, but the whole organism sometimes causing headaches, auditory problems 
and back pain.

The malocclusion affects not only the masticatory functionality but also the aesthetics, resulting in an asymmetrical face. In the most serious malocclusions, the aesthetic defect is particularly evident, so as to create social and relational problems.

Class III malocclusion is usually treated using the Petit protraction facemask composed of a forehead support and a chin cup made from acrylic, connected by a midline stainless steel rod. Two elastic bands connect the mask to an intraoral anchor applying a force of about 500-600 gr. In this way, the facemask anteriorly displaces the superior maxilla or stimulates its growth in that direction. The orthodontic treatment has been proven effective if the facemask is worn at least fourteen hours a day for at least nine months (Menéndez-Díaz et al., 2018).

In a survey assessing the acceptability of different orthodontic appliances (Abu Alhaija \& Karajeh, 2013), the facemask was ranked as the least accepted and the least attractive appliance among ten different intra-oral and extra-oral appliances. Age, gender, type of school and living backgrounds did not affect acceptance of facemask.

Factors affecting the acceptance of facemask include the hindering of daily activities, poor ergonomics and aesthetics, skin irritation caused by the direct contact of plastic with the skin, and shame. Children often complain about the mask's bulkiness and instability, while doctors have often to adapt the facemask using soft paddings under the chin cup and forehead supports or reducing the length of the midline stainless steel rod.

\section{Design Thinking Process}

Even if different Design Thinking process models exist, overall, they share five key principles (Carlgren et al., 2016): problem framing, user focus, multidisciplinary teams of people, making abstract ideas visible and tangible, incremental improvement of created solutions through criteria-led testing phases.

In our project, we adopted an iterative Design Thinking process model as defined by the Hasso-Plattner Institute of Design (2021) at Stanford (d.school) and illustrated below.

\section{Empathise}

Empathy is a fundamental step in Design Thinking. It is the ability to immerse in the lived experience of people to share their feelings and communicate that understanding. This involves consulting experts, observing, engaging people to learn from their experiences and motivations, as well as digging deep in the physical/ social environment to gain a deeper personal understanding of the challenges.

In our project, the design team included three orthodontists, two designers, two experts in 3D modelling and rapid prototyping, two engineers and one graphic designer.

Co-design was fundamental for the project and involved ortho- 
dontists, children, and their families. It took several forms from the development of a concept video to inspire the design team and stimulate debate with a narrative approach (Marti, 2018), to the collection of Cultural Probes (Gaver et al., 1999).

Cultural Probes were designed and distributed to five families with children who were undergoing the therapy with the facemask, to gather inspirational data. Unfortunately, only two families responded, providing us with probes collected by their children (a girl and a boy). Parents were instructed to help their children answer some questions by taking photos or recording simple voice or written messages and return them via WhatsApp. The questions were related to their experience with the facemask, their favourite colours, clothes and accessories, games, and fantasy characters.

Both children reported to feel listless when wearing the facemask and happy after having removed it. Their favourite colours were red and glittered pink, their favourite carnival masks were punk rock and Stitch (Walt Disney). The probes revealed curiosity for new games and sensitivity to details of their clothing. Their feelings about the facemask were not positive and they felt not motivated to wear it. They never wore the mask during the day.

\section{Define}

From the insights and after several brainstorming sessions with orthodontists, we defined the challenge of the project. This phase was conducted sharing the experience of the orthodontists in treating young patients with mandibular malocclusion. In addition to the problems reported by a literature review, the team realised that commercial facemasks have no gendered body design, the design is overall boring and purely functional, and the long duration of the treatment generates frustration and poor patient compliance. Furthermore, the orthodontists reported difficulties in monitoring the progress of the therapy since possible missed results can be due to the ineffectiveness of the mask or the fact that the child does not wear it as prescribed.

Three main areas of a possible new design of the facemask were identified:

1 gamification of the therapy to make it more attractive, motivating and engaging;

2 improvements of the ergonomics, materials, aesthetics;

3 monitoring of the therapy.

Ideate

According to the challenges of the project, a new and more holistic concept of therapeutic intervention was defined consisting of the following components Fig. 1. 


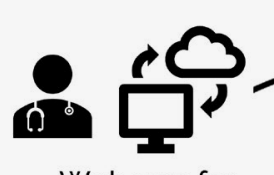

Web app for

monitoring the therapy

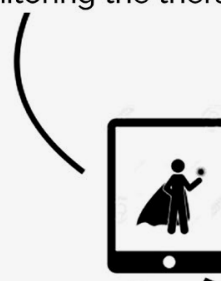

Game

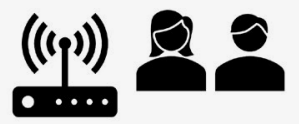

Docking station to download data and recharge the unit

The figu e shows the system components. (C) 2021 All rights reserved.

- $\quad$ Personalized facemask printed in biocompatible resin and customizable with different colours and embellishment elements made of fabric portraying a superhero mask. The facemask is designed to fit the anatomy of the child's face and embeds electronics to monitor the wear time. Docking station to recharge the battery of the facemask, download the data and send them via Wi-Fi connection to the backend database.

Video game connected to the use of the facemask developing in various adventures lasting several months (at least nine months which is the duration of the therapy).

Web app used by the orthodontist to monitor the progress of the treatment based on accurate data on the wear time.

\section{Prototype}

An intense iterative phase of prototyping was carried out to materialise the system's components, to evaluate alternative designs and get inspiration throughout testing and refining.

\section{Game design}

An online survey was conducted involving 145 children who responded to open-ended and closed-ended questions regarding their preferences related to superheroes.

Children's age spanned from five to ten years (average age $7.5)$ equally distributed between males (53\%) and females (47\%).

The results show that $69 \%$ of respondents chose their favourite superheroes for their powers, for the special characteristics that make them unique (e.g., Storm can control atmospheric elements; Mystique can camouflage and take any aspect). 
Children demonstrated to be very sensitive to clothing and to have very precise tastes. For about $41 \%$, the disguises, masks and colours affected the choice of the favourite character: Batman is black and "has many technological gadgets"; Ironman has "a beautiful steel armour".

Among the characteristics indicated by $27 \%$ of children, the role the hero plays in society is fundamental: Wonder Woman "is a strong and courageous woman, she never gives up"; Spiderman "helps the weak and defends the city".

The physical aspect is an important element for $26 \%$ of the respondents: Catwoman is beautiful and elegant, Hulk is muscular. Children pay a lot of attention to accessories and clothing.

The outcomes of the questionnaire inspired the game design.

The first prototype of the game was a single never-ending plot in which the main character, elf Araton, fights against evil creatures Fig. 2. The scoring system depended on the facemask wear time and the game play corresponding to 1 point for each defeated enemy. A simulated version of this game was developed and widely debated within the team and with some families. It disclosed some weaknesses. First, the concept was based on the story of the elf Araton, which constrained the design of the facemask to the "elf world". Secondly, the scoring system based on the game play can cause prolonged exposure to the video game and consequent concerns of the parents.
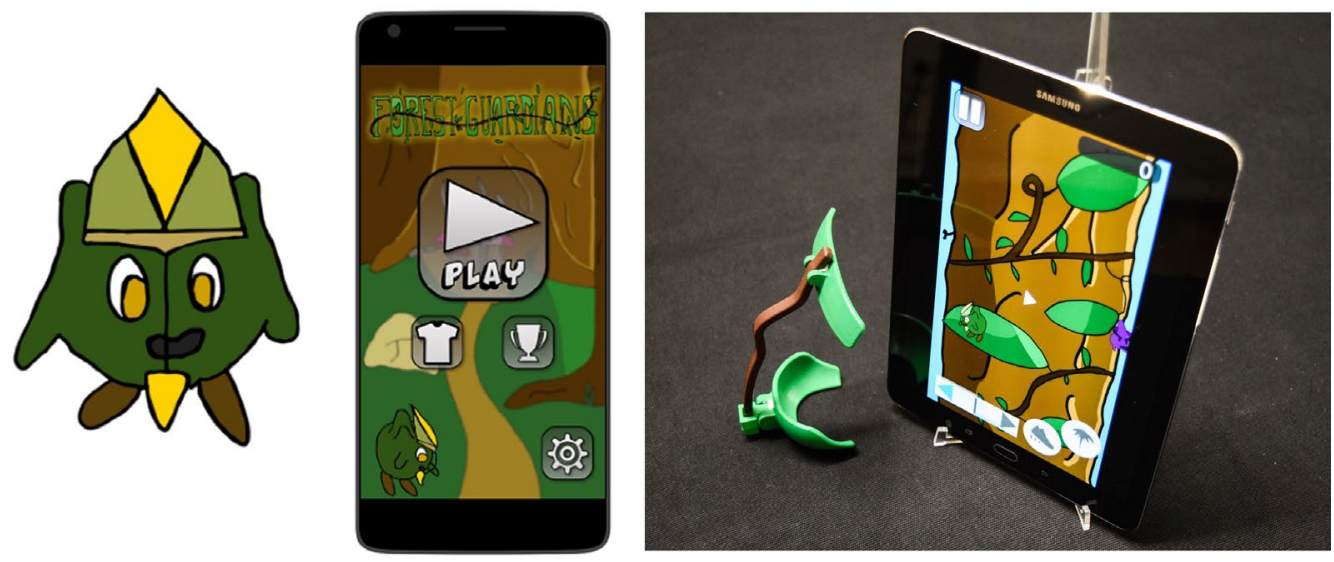

The next iteration of game design adopted a different approach based on the model of the idle game. The game consists of a main storyline: Naturalia is a magical place where people and nature coexist peacefully. One day, a company of unscrupulous people arrives to exploit the natural resources of Naturalia's forest: they cut down trees to make furniture, collect fruits to sell in plastic bags, and build skyscrapers and parking lots. All the animals are forced to flee the forest.

Fig. 2

Santa Chiara Fab Lab. The figu e shows the Elf Araton (left), the game start (centre), the video game and the facemask (right). (C) 2021 All rights reserved. 
Four superheroes fight to save nature Fig. 3. They are designed according to the insights from the online survey and the cultural probes.

Greta is a warrior who fights with a sword and can practice magic against her enemies.

Beck is a clever young boy, fluent in math and very agile; he can sabotage machines.

Johnny 6 is a robot working for the company and specialized in destroying trees; following a short circuit, it uses its skills to save the forest removing waste and building shelters for animals.

Andrea is a morphing creature: they are a human who can turn into different types of animals.

The superheroes wear colourful costumes, with several accessories Fig. 3 (left). They all wear a facemask to facilitate identification and connection with the child.
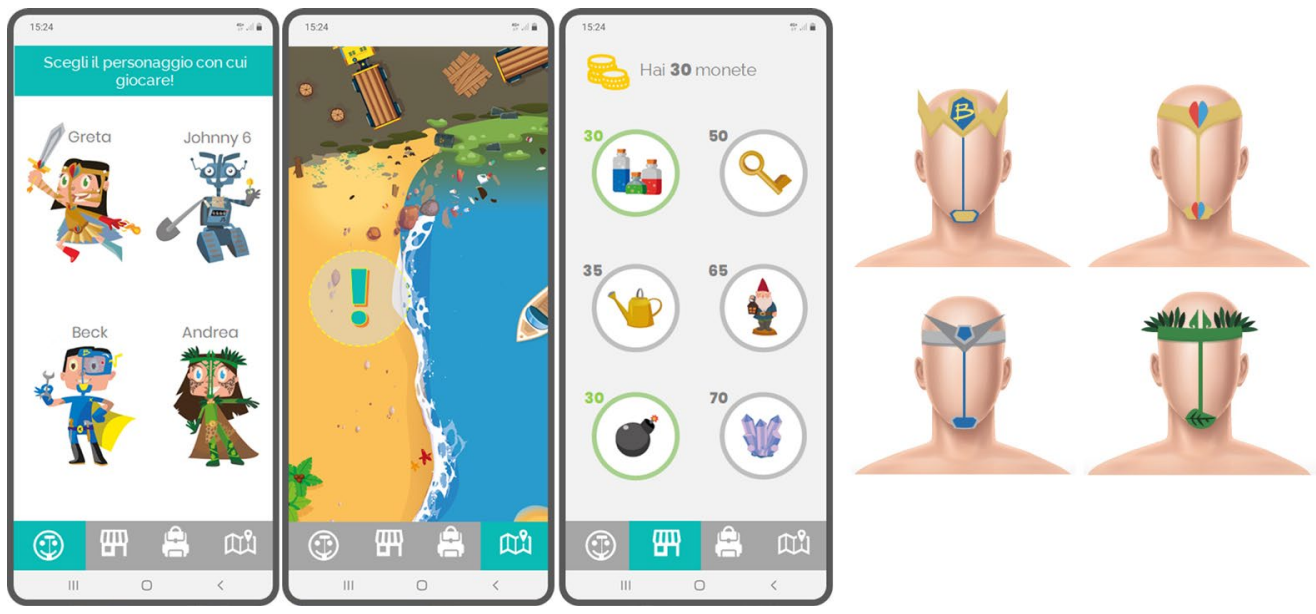

Wearing the mask for a variable number of hours, the child earns coins to buy useful tools used by the superheroes to proceed in the adventure Fig. 3 (left). Reinforcement and reward nudges are received all along the game to encourage the child to keep on wearing the facemask.

The game is designed for a sporadic and non-continuous use: once the coins are spent, the child must wait to earn other coins to avoid excessive use of the video game. Waiting times are designed to last the entire duration of the therapy, at least 9 months.

The digital game is completed by physical accessories that can be mounted on the facemask to embellish it Fig. 3 (right). These are made of laser cut felt and fixed to the facemask with velcro.
Fig. 3

Santa Chiara Fab Lab. The figu e shows screenshots of the adventure game (left) and the accessories to decorate the facemask (right) (c) 2021 All rights reserved. 


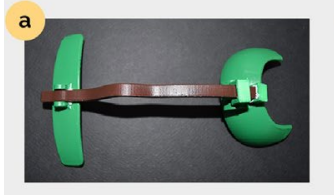

Material: PLA

Measures: $9 \times 17 \mathrm{~cm}$;

$23.4 \mathrm{gr}$.

Description: early prototype. exploration of form and weight.

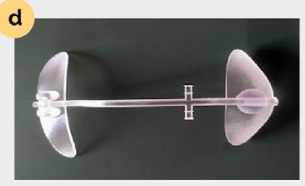

Material: MED610

Measures: $9 \times 17 \mathrm{~cm} ; 7.2 \mathrm{gr}$.

Description: mask printed with a biocompatible resin; the model complies with all the requirements: strength, comfort, biocompatibility.

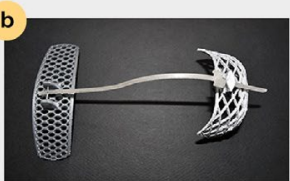

Material: PLA

Measures: 9x16.8 cm: $7.5 \mathrm{gr}$

Description: skeleton of the facemask with holes to make it breathable and light. The design was abandoned since the holes could leave marks on the skin and the chin cup did not adequately fit the child's chin.

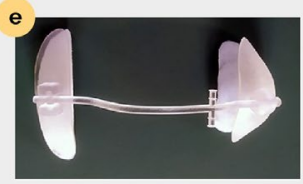

Material: MED610, TPU Bioflex

Measures: $9 \times 17 \mathrm{~cm} ; 9.5 \mathrm{gr}$.

Description: two soft pads made of biocompatible material were inserted in the forehead support and chin cup to improve comfort.

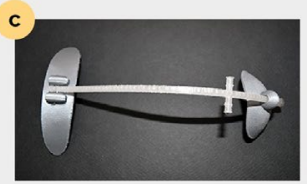

Material: Nylon PA12, ASA Measures: $9 \times 16.4 \mathrm{~cm}$; $9.1 \mathrm{gr}$.

Description: mask printed with a biocompatible material. The prototype was discarded. PA12 nylon printed with a FDM printer can cause abrasion on the skin

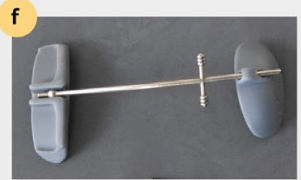

Material: BioMed Clear Resin; Stainless steel Measures: $9 \times 17 \mathrm{~cm} ; 70 \mathrm{gr}$.

Description: biocompatible resin, resistant to

mechanical stress, resulting in a uniform surface. The steel is robust and light.

\section{The custom facemask}

The custom facemask underwent a long prototyping process including several iterations to identify the more suitable material and the manufacturing methodology Fig. 4.

Six different materials were identified for the 3D printing and tested for their flexibility, weight, comfort, suitability for long-term skin contact. These include ASA (Acrylonitrile Styrene Acrylate) used for the central bar and discarded since it is not biocompatible; MED610 which is biocompatible and resistant to mechanical stress but expensive; Bioflex TPU (Thermoplastic Polyurethane), a soft, flexible and elastic material that we used to print soft and thin pads for insertion inside the forehead support and chin cup to improve comfort on the skin. This material was then substituted by Silipos that has similar features but is cheaper; and FormLabs BioMed Clear Resin, a rigid, non-brittle, biocompatible resin suitable for long-term skin contact, which was revealed to be ideal for our purposes.

Regarding the manufacturing methodology, the custom facemask is built from the digital scan of the child's face that can be obtained with different alternative methods: a multi-camera photogrammetric system with nine high-resolution cameras connected to a photogrammetric software, a camera TrueDepth and Bellus3D software on iPhone X or higher or iPad Pro tablet. All methods were tested extensively and proved to be suitable for our purposes. 
The 3D model of the patient's face is then prepared to obtain two different physical objects:

1 an early prototype of the facemask printed with a Fused Deposition Material (FDM) printer in Polylactic acid (PLA) material, which is cheap, easy and fast to print; a replica of the child's face built in polystyrene using a CNC machine, used to check the adherence of the facemask to the child's face Fig. 5 (left). Several prototypes of facemask can be iteratively printed until it perfectly fits the replica.
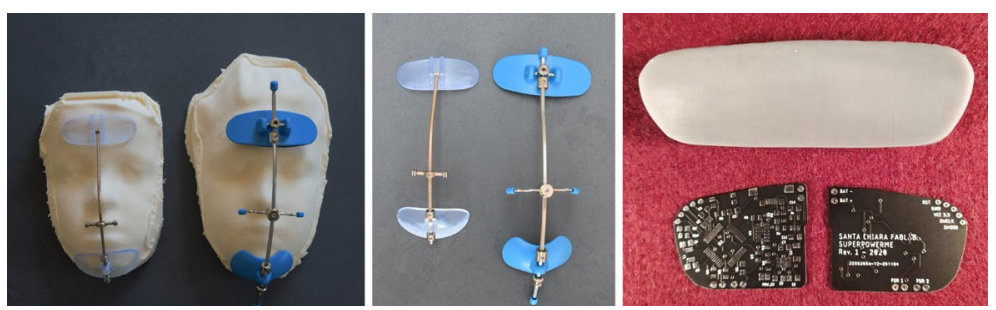

The final facemask is printed using a stereolithographic 3D printer and the biocompatible Biomed Clear resin produced by Formlabs (Somerville, MA, USA). The forehead support and chin cup are lined with a biocompatible polymeric pad to improve softness, produced by the company Silipos (Niagara Falls, NY, USA). These pads are already used in orthopaedics and dermatology for its moisturizing and soothing action on the skin (Cordasco et al., 2014).

The central bar is printed in stainless steel.

Compared to the Petit commercial facemask, the custom facemask is smaller and lighter. The use of biocompatible material and the customisation avoid skin irritations and bulkiness.

The electronic system

A temperature sensor, a pressure sensor and an accelerometer are integrated in the forehead support of the mask, together with one small LiPo battery, a flexible micro-PCB Fig. 5 (right). The redundant use of three different sensors allows us to monitor the wear time ensuring data tracking even in the event of a malfunction of one of the sensors.

Data collected by the sensors are downloaded when the mask is placed on a docking station and sent via Wi-Fi to a remote database. The docking station is also used to recharge the batteries.

The data contained in the database are visualised through a web application that the doctor can use to monitor the therapy. The web app allows the doctor to enter the data of the patient and displays data about the wearing time of the facemask along the entire duration of the therapy.

Fig. 5

Santa Chiara Fab Lab. The figu e shows the custom facemask compared to the Petit facemask (left and centre) and the embedded electronic (right). The comparison between the Petit facemask and the Custom facemask (left and centre): weight (P 74 gr. C 34 gr.), forehead support $(P 8.7 \mathrm{~cm} \times$ $3 \mathrm{~cm} \mathrm{C} 7.1 \mathrm{~cm} \times 2.9 \mathrm{~cm}$ ), chin cup (P $5.9 \mathrm{~cm} \times 3.7$ $\mathrm{cm} \mathrm{C} 6.15 \mathrm{~cm} \times 3.25 \mathrm{~cm}$ ), lenght (P $22 \mathrm{~cm} \mathrm{C} 16 \mathrm{~cm})$. (C) 2021 All rights reserved. 


\section{Evaluation}

A clinical trial is currently ongoing at the University of Firenze (Dipartimento di Medicina Sperimentale e Clinica, SOD Odontostomatologia, Ambulatorio di Ortognatodonzia, AOU Careggi) and the Stomatološki Fakultet Univerziteta of Beograd. The clinical trial was approved by the Pediatrics Ethical Committee of the Tuscany Region.

The trial is designed as an interventional study involving ten patients (five in Italy, five in Serbia). It aims to clinically evaluate the custom facemask for the treatment of Class III malocclusion in fivenine years old patients.

The hypothesis of the study is that the custom facemask is comfortable and favourably accepted by the patient, with the desirable effect of obtaining a more regular, prolonged, and therefore more effective use of the device. The study also aims to detect any complications that may arise during therapy with the custom facemask.

Each patient will be treated with the custom facemask for a period of ten months. At the end of the first week, after three months, after six months and at the end of the therapy (after ten months) the patients will be requested to fill in a questionnaire designed by the orthodontics, with the help of the parents, to investigate their experience with the facemask.

So far, we have collected data from five patients: two children filled in the questionnaire after one week, two children after one week and three months, one child after one week, three months and six months. Even if it is impossible to draw conclusions with these few data, we report below some early outcomes.

The perceived pain on a Pain Visual Analogue Scale (Huskisson, 1974) from 0 to 10 decreased for Patient-1 from 2,5 to 1,5 in six months; for Patient-2 from 1,5 to 0 in three months, for Patient-3 from 5 to 1 in three months. The other 2 patients reported 0 and 2 after one week. Only one patient reported nocturnal awakens due to the intraoral maxillary expander. No inconvenience due to the facemask was reported.

Patient-3 wore the facemask for nine hours a day in the first week and eleven hours a day after three months.

Two facemasks were replaced because of minor rifts of the forehead support.

On average, the daily wear time is ten hours which is below the minimum prescribed of twelve hours. We hope to improve this data with the introduction of the video game in the next clinical trial already approved by the Ethical Committee. 


\section{Conclusions}

Design thinking is a problem-solving strategy allowing participants in the design process to break out of the natural patterns of their activity and think "out of the box". It helps people to take a point of view which is not rooted in repeated behaviours and attitudes routinely accumulated in our life. On the contrary, it stimulates people in confronting new challenges and thinking holistically at the human experience.

The design case study described in this paper shows how Design Thinking helped in re-framing the problem of low acceptance and scarce ergonomics and aesthetics of the orthodontic device in a human-centric way, developing ideas, and adopting a practical approach in prototyping and testing.

The approach proved to be an iterative and agile process of ongoing experimentation using the methods of design to empathise with people, try out concepts and ideas, prototype and test them in the real world.

The human centric point of view allowed a fundamental shift from a purely functional view of therapy to a value-based care focused on building around the needs, habits and expectations of doctors, children, and their families.

Co-design and co-creations also allowed a shift from viewing patients and doctors as consumers of solutions to being active stakeholders in the design activity where everyone is empowered to contribute with their knowledge of the problem to solve.

As a process, Design Thinking can play a role of catalyst for change and evolution bringing together people with different backgrounds and creating a space for sharing of ideas and building of innovative solutions that have the broadest possible support at their inception (in our case doctors, children, families, hospital).

\section{Patrizia Marti}

Associate Professor at the Università degli Studi di Siena. She is Director of Santa Chiara Fab Lab where she manages participatory innovation projects. She has an interdisciplinary background in design and computing and a Ph.D. in Interaction Design. Her research activity concerns designing systems facing cultural, aesthetic and social issues through embodied experiences.

\section{Flavio Lampus}

Research Assistant at the Università degli Studi di Siena. He has an interdisciplinary background in computing and humanities. He is expert in digital fabrication with a Diploma of Fab Academy, the World Academy of Digital Manufacturing. His research at the Università degli Studi di Siena includes projects concerning the use of digital fabrication for medical applications.

\section{Annamaria Recupero}

Ph.D. in Psychology, is a Post-doc Researcher at the Department of Social Political and Cognitive Sciences, Università degli Studi di Siena. She collaborates with the Santa Chiara Fab Lab in research projects applying design thinking and co-design methods.

\section{Lorenzo Franchi}

Associate Professor at the Università degli Studi di Firenze and Visiting Scholar at the University of Michigan, USA. He teaches Orthodontics and Dentofacial Orthopaedics at the Università degli Studi di Firenze. He is Associate Editor of the European Journal of Orthodontics. His research interests are early treatment, treatment timing and dentofacial orthopaedics.

\section{Cecilia Goracci}

Associate Professor at the Università degli Studi di Siena. She has a Degree in Dentistry, a Specialty in Orthodontics and a Ph.D. in Dental Materials. At the Department of Medical Biotechnologies of the Università degli Studi di Siena she conducts teaching and research activities in the fields of Dental materials, Biostatistics and Epidemiology, while her clinical practice focuses on Orthodontics. 


\section{Acknowledgement}

The project is covered by patent number 102018000002713 ; inventors: Prof. Cecilia Goracci, Prof. Patrizia Marti, Prof. Lorenzo Franchi, Ing. Matteo Sirizzotti, Prof. Alessandro Vichi.

The project received funding from Intesa Sanpaolo and

Pocarno-MISE (Italian Ministry of Economic Development). The authors thank Pietro Rustici who implemented the game platform.
Simone Guercio

Collaborates with the Santa Chiara Fab Lab, Università degli Studi di Siena, as an expert in rapid prototyping, hardware and software design. He is the local instructor of Fab Academy, the World Academy of Digital Manufacturing, teaching digital fabrication techniques to students and young professionals.

\section{Alessandro Vichi}

Senior Lecturer at the Dental Academy of the University of Portsmouth, UK, and Coordinator of the Master of Science in Advanced Aesthetic and Restorative Dentistry. He authored over 250 scientific publications and gave over 300 lectures and courses worldwide in Dental Materials, Restorative Dentistry and Prosthodontics.

\section{References}

Abu Alhaija, ES, \& Karajeh, M. A. (2013). Acceptability and attractiveness of intra-and extra-oral orthodontic appliances. International journal of orthodontics, 24(1), 11-17.

Altman $\mathrm{M}$, Huang TT, \& Breland JY. (2018). Design Thinking in Health Care. Preventing Chronic Disease, 15, E117. https:// www.cdc.gov/pcd/issues/2018/18_0128.htm

Baker III, F. W., \& Moukhliss, S. (2020). Concretising Design Thinking: A Content Analysis of Systematic and Extended Literature Reviews on Design Thinking and Human-Centred Design. Review of Education, 8(1), 305-333. https://doi. org/10.1002/rev3.3186

Bellus 3D. (2021, September 14). https://www. bellus3d.com/

Brown, T. (2009). Change by Design: How Design Thinking Transforms Organizations and Inspires Innovation. Harper Business.
Buchanan, R. (1992). Wicked problems in design thinking. Design issues, 8(2), 5-21.

Carlgren, L., Rauth, I., \& Elmquist, M. (2016). Framing design thinking: The concept in idea and enactment. Creativity and Innovation Management, 25(1), 38-57. https://doi. org/10.1111/caim.12153

Cooper, R. (2019). Design research - Its 50-year transformation. Design Studies, 65, 6-17. https:// doi.org/10.1016/j.destud.2019.10.002

Cordasco, G., Matarese, G., Rustico, L., Fastuca, S. Caprioglio, A., Lindauer, S. J., \& Nucera, R. (2014) Efficacy of orthopedic treatment with protraction facemask on skeletal Class III malocclusion: a systematic review and meta-analysis. Orthodontics \& Craniofacial Research, 17(3), 133-143. https://doi.org/10.1111/ ocr.12040
Gaver, B., Dunne, T., \& Pacenti, E. (1999). Design: cultural probes. interactions, 6(1), 21-29. https://doi. org/10.1145/291224. 291235

Hasso-Plattner Institute. (2021, September 14). The six phases of the Design Thinking process. https:// hpi.de/en/school-of-designthinking/design-thinking/ background/design-thinking-process.html

Huskisson, E. C. (1974). Measurement of pain. The lancet, 304(7889), 11271131.

Johansson-Sköldberg, U., Woodilla, J., \& Çetinkaya, M. (2013). Design thinking: past, present and possible futures. Creativity and innovation management, 22(2), 121-146. https://doi. org/10.1111/caim.12023

Ku, B., \& Lupton, E. (2020). Health Design Thinking: Creating Products and Services for Better Health. MIT Press.
Marti, P. (2018, may 9). SuperPowerMe [Video] Vimeo. https://vimeo. com/268795652

Menéndez-Díaz, I., Muriel, J., Cobo, J. L., Álvarez, C., \& Cobo, T. (2018). Early treatment of C lass III malocclusion with facemask therapy. Clinical and experimental dental research, 4(6), 279-283. https://doi. org/10.1002/cre2.144

Verganti, R. (2008). Design, meanings, and radical inno vation: A metamodel and a research agenda. Journal of product innovation management, 25(5), 436-456. https://doi.org/10.1111/ j.1540-5885.2008.00313.x

Zere, E., Chaudhari, P. K., Sharan, J., Dhingra, K., \& Tiwari, N. (2018). Developing Class III malocclusions: challenges and solutions. Clinical, cosmetic and investigational dentistry, 10, 99-116. https://doi. org/10.2147/CCIDE. $\mathrm{S} 134303$ 